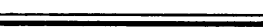

\title{
Measurement of brain tissue oxygen at a carbon paste electrode can serve as an index of increases in regional cerebral blood flow
}

\author{
John P. Lowry,*, Martyn G. Boutelle ${ }^{\mathrm{b}}$, Marianne Fillenz ${ }^{\mathrm{a}}$ \\ ${ }^{a}$ University Laboratory of Physiology, Parks Road, Oxford OX1 3PT, UK \\ ${ }^{\mathrm{b}}$ Department of Chemistry, King's College London, Strand, London WC2R 2LS, UK
}

Received 1 April 1996; revised 17 July 1996; accepted 1 August 1996

\begin{abstract}
Simultaneous monitoring of tissue $\mathrm{O}_{2}$ and regional cerebral blood flow (rCBF) was performed in the striatum of freely-moving rats. Differential pulse amperometry and constant potential amperometry were used to monitor $\mathrm{O}_{2}$ levels at a carbon paste electrode (CPE), while rCBF values were obtained using the $\mathrm{H}_{2}$ clearance technique. Two forms of behavioural activation were studied and the resultant changes in tissue $\mathrm{O}_{2}$ and blood flow compared. Both tail pinch and induced grooming produced immediate and parallel increases in $\mathrm{O}_{2}$ and blood flow which returned to baseline on cessation of activity. These findings indicate that under conditions of physiological stimulation the direct voltammetric measurement of $\mathrm{O}_{2}$ in brain tissue with a CPE can be used as a reliable index of increases in $\mathrm{rCBF}$, resulting in an improvement in time resolution from $5 \mathrm{~min}\left(\mathrm{H}_{2}\right.$ clearance) to $<1$ $\mathrm{s}$ (amperometry). Because tissue $\mathrm{O}_{2}$ is a balance between supply by the blood stream and utilisation by the cells, increases in $\mathrm{O}_{2}$ current are an index of increased blood flow only when supply significantly exceeds utilisation. (C) 1997 Elsevier Science B.V.
\end{abstract}

Keywords: Oxygen; Cerebral blood flow; Carbon paste electrodes; Hydrogen clearance; Physiological stimulation; Rat brain

\section{Introduction}

Local blood flow is most commonly measured using the hydrogen $\left(\mathrm{H}_{2}\right)$ clearance technique, a method first introduced 30 years ago (Aukland et al., 1964; Aukland, 1965). $\mathrm{H}_{2}$ gas is administered by inhalation, and once administration has stopped, its rate of clearance, which is proportional to local blood flow, is monitored amperometrically at a Pt microelectrode. The technique is simple and inexpensive to implement and allows multiple in situ recording from any tissue in which a small electrode can be implanted. A comprehensive review of the technique has been published by Young

\footnotetext{
* Corresponding author. Present address: Department of Chemistry, University College Dublin, Belfield, Dublin 4, Ireland. Tel. +35317062274 or 7062300 ; fax: + 35317062127 ; e-mail: jlowry@acadamh.ucd.ie.
}

(1980) where possible sources of error have been examined.

A number of groups have used the technique to monitor regional cerebral blood flow (rCBF) (Fieschi, 1966; Gotoh et al., 1966; Haining et al., 1968). Due to difficulties associated with the administration of the $\mathrm{H}_{2}$ tracer, the technique has been limited to rCBF measurements in anaesthetised animals. Attempts to adapt the technique for use in awake animals have involved confining the animals in a vented chamber through which a $\mathrm{H}_{2}$-air mixture is passed at high volume flow rate (Endo et al., 1990; Bray et al., 1991). This, however, gives poor time resolution and is potentially stressful. More recently, a novel $\mathrm{H}_{2}$ delivery system that directs a slow stream of pure $\mathrm{H}_{2}$ at an animals snout for $10-20 \mathrm{~s}$ has been developed in this laboratory (Fellows and Boutelle, 1993); this allows rCBF measurements to be made at 5-min intervals in the undisturbed, freely moving animal. 
An alternative to measuring clearance from the tissue is to measure changes in the concentration of a substance delivered to the tissue by the blood stream. The most important substrate for energy metabolism delivered by the blood stream is $\mathrm{O}_{2}$. However, tissue concentration is determined by the balance between supply and utilisation. The use of a number of techniques has shown that during neuronal activation there is a rise in local $\mathrm{O}_{2}$ concentration because of a greater increase in rCBF than $\mathrm{O}_{2}$ utilisation (Leniger-Follert and Lübbers, 1976; Fox et al., 1988; Zimmerman et al., 1992). We have previously reported the development of a voltammetric technique with subsecond time resolution for the direct measurement of tissue $\mathrm{O}_{2}$ at a carbon paste electrode (Lowry et al., 1996). In the present study we have compared the in vivo measurement of $\mathrm{H}_{2}$ clearance at a platinum electrode with the measurement of changes in tissue $\mathrm{O}_{2}$ at a carbon paste electrode in the striatum of freely moving rats during behavioural activation. The results suggest that under such conditions the direct measurement of $\mathrm{O}_{2}$ increases can be used as a reliable index of increases in $\mathrm{rCBF}$.

\section{Methodology}

\subsection{Working electrode preparation}

The $\mathrm{H}_{2}$ detection electrode was made from 2T (50$\mu \mathrm{m}$ bare diameter, $75-\mu \mathrm{m}$ coated diameter) tefloncoated platinum/iridium ( $\mathrm{Pt} / \mathrm{Ir} 90 \% / 10 \%)$ wire (Advent Research Materials, Suffolk, UK). A section of the teflon was carefully cut from the end of the wire to produce a 4-mm active length of bare wire. To facilitate implantation, the wire was glued into a $20-\mathrm{mm}$ length of plastic-coated silica tubing (O.D. $0.17 \mathrm{~mm}$; Scientific Glass Engineering, Milton Keynes, UK) and a 14-mm section of stainless steel cannula (O.D. $0.5 \mathrm{~mm}$; Goodfellow, Cambridge, UK). Only the bare Pt wire and 2 $\mathrm{mm}$ of the silica tubing penetrated the brain (Fellows and Boutelle, 1993).

Carbon paste electrodes (CPEs) were made from $5 \mathrm{~T}$ (125- $\mu \mathrm{m}$ bare diameter, $160-\mu \mathrm{m}$ coated diameter) teflon-coated silver wire (Advent Research Materials, Suffolk, UK). The teflon insulation was slid along the wire to create an approximately 2-mm deep cavity which was packed with carbon paste using a bare silver wire as plunger. Carbon paste was prepared by thoroughly mixing $2.83 \mathrm{~g}$ of carbon powder (UCP-1-M, Ultra Carbon Corp., Bay City, MI, USA) and $1.0 \mathrm{ml}$ of silicone oil (Aldrich, Catalogue No. 17,563-3) (O'Neill et al., 1982). All electrodes were soldered to gold connectors, which were cemented into a six-pin plastic socket (both from Plastics One, Roanoke, VA, USA).

\subsection{Voltammetric techniques}

Changes in $\mathrm{O}_{2}$ at implanted CPEs were monitored using differential pulse amperometry (DPA). This involves the application of two equally sized potential pulses, the first from a resting potential at $-150 \mathrm{mV}$ to $-350 \mathrm{mV}$ that corresponds to the foot of the reduction wave for $\mathrm{O}_{2}$ at CPEs, and the second from $-350 \mathrm{mV}$ to $-550 \mathrm{mV}$ that corresponds to the peak of the reduction wave. The difference in the current $(\Delta I)$ sampled during these pulse pairs was calculated and changes in $\Delta I$ used as a measure of interference free changes in $\mathrm{O}_{2}$ (Lowry et al., 1996).

Constant potential amperometry (CPA), where the detecting electrode is held at a constant potential sufficient to detect the oxidation or reduction of the target substance, was used for $\mathrm{H}_{2}$ oxidation with the $\mathrm{Pt} / \mathrm{Ir}$ electrode being held at $+250 \mathrm{mV}$. At this potential, detection of $\mathrm{H}_{2}$ is mass transport-limited and is not compromised by detection of other oxidisable species present in the brain (Fellows and Boutelle, 1993). CPA was also tested for the detection of $\mathrm{O}_{2}$ by holding the $\mathrm{CPE}$ at the peak potential for $\mathrm{O}_{2}$ reduction $(-550$ $\mathrm{mV})$.

All potentials were applied with respect to a silver wire (200- $\mu \mathrm{m}$ bare diameter; Advent Research Materials, Suffolk, UK) reference electrode implanted in the cortex. The reference potential provided by the silver wire in brain tissue is very similar to that of the saturated calomel electrode (SCE) (O’Neill, 1993). Auxiliary and earth electrodes were also of $200 \mu \mathrm{m}$ silver wire.

\subsection{Surgical procedures}

Male Sprague-Dawley rats $(200-300$ g) were anaesthetised with a combination of fentanyl/fluanisone $(0.25 / 0.8 \mathrm{mg} / \mathrm{kg}$ i.p. $)$ and midazolam $(0.4 \mathrm{mg} / \mathrm{kg}$ i.p. $)$ and placed in a stereotaxic frame. Body temperature was maintained at $37^{\circ} \mathrm{C}$ with a heating pad (Braintree Scientific, Braintree, MA, USA). The CPE was implanted in the left striatum (coordinates with the skull levelled between bregma and lambda were: $\mathrm{A} / \mathrm{P}+1.0$ from bregma, $\mathrm{M} / \mathrm{L}-2.5$, and $\mathrm{D} / \mathrm{V}-5.0$ from dura). The $\mathrm{Pt} / \mathrm{Ir}$ electrode was implanted in the right striatum (coordinates with the skull levelled between bregma and lambda were: $\mathrm{A} / \mathrm{P}+1.0$ from bregma, $\mathrm{M} / \mathrm{L}+2.5$, and $\mathrm{D} / \mathrm{V}-8.5$ from dura). The reference electrode was placed in the cortex, the auxiliary electrode placed between the skull and dura, and an earth wire attached to one of the support screws. The electrodes were fixed to the skull with screws (Oxford Seals and Bearings, Oxford, UK) and dental acrylate (Associated Dental Products Ltd, Swindon, UK).

Post-operative analgesia was provided in the form of a single injection of buprenorphine $(0.1 \mathrm{mg} / \mathrm{kg}$ s.c. $)$ 
given immediately following the surgery. The rats were housed in large plastic bowls (Johnson's Garden Centre, Oxford), with free access to food and water. Animals were given $24 \mathrm{~h}$ to recover after surgery. Experiments were carried out with the animal in its home bowl. The health of the animals was assessed according to published guidelines (Morton and Griffiths, 1985; Wolfensohn and Lloyd, 1994) and all procedures were specifically licensed under the Animals (Scientific Procedures) Act, 1986.

\subsection{Instrumentation and software}

A specially designed low-noise potentiostat (Biostat II, Electrochemical and Medical Systems Ltd, Newbury, UK) was used in all experiments. For CPA experiments data acquisition was carried out through an NB-MIO-16X multifunction data acquisition board (National Instruments (NI) Corp., Austin, TX, USA) in a Macintosh IIx computer and was controlled using in house written LabVIEW (NI, version 2.2.1) software. Current values were sampled every $2 \mathrm{~ms}$ and averaged by the computer at 0.5 -s intervals.

For DPA experiments data acquisition was performed on a Mitac 486 PC through an AT-MIO-16 data acquisition board. In house software was written in the LabWindows (NI, version 2.1) QuickBASIC environment. Data sampling was performed at a rate of 250 points/pulse/100 ms and averaged to give 1 point/ pulse/s (Lowry et al., 1996). A complete pulse sequence was performed every $2 \mathrm{~s}$.

All analysis was performed using both in house developed software and the commercial package Igor Pro 2.0 (WaveMetrics Inc., USA). Statistics were performed using the Student's $t$-test (StatView, Abacus Concepts, Inc., CA, USA) for paired observations. Two-tailed levels of significance were used and $P<0.05$ was considered to be significant. Values are presented as mean \pm S.E.M.

\subsection{Experimental conditions}

At least 90 min prior to the start of each blood flow experiment, the rat was placed in a fume cupboard, in its home bowl. The electrodes were connected to the potentiostat through a flexible cable and swivel (Plastics One, Roanoke, VA, USA) which allowed the animal free movement. Once the background current for the $\mathrm{Pt} / \mathrm{Ir}$ electrode had stabilised (typically $30 \mathrm{~min}$ ) and the rat had become accustomed to the new conditions, blood flow measurements were made (5-min intervals). The $\mathrm{O}_{2}$ signal from the CPE stabilised within $5 \mathrm{~min}$ for both CPA and DPA techniques and was recorded continuously (2-s intervals).

Post in vivo calibrations of CPEs were performed immediately after the death of the animals. The elec- trodes were placed in a standard three-electrode glass electrochemical cell containing $30 \mathrm{ml}$ phosphate buffered saline (PBS), pH 7.4; $\mathrm{NaCl}$ (Merck, BP USP grade, $0.15 \mathrm{~mol} / \mathrm{l}), \mathrm{NaH}_{2} \mathrm{PO}_{4}(\mathrm{BDH}$, AnalaR grade, $0.04 \mathrm{~mol} / \mathrm{l}$ ) and $\mathrm{NaOH}(\mathrm{BDH}, \mathrm{GPR}$ grade, $0.04 \mathrm{~mol} / \mathrm{l})$. A saturated calomel electrode (SCE) was used as the reference electrode, and a large silver wire, isolated in a compartment containing PBS, served as the auxiliary electrode. The current was recorded in PBS saturated with either $\mathrm{N}_{2}$ (British Oxygen Co. (BOC), Guildford, UK), air (RENA 102 air pump, Tesco's Garden Centre, Abingdon, UK) or $\mathrm{O}_{2}$ (BOC), where the concentration of solution $\mathrm{O}_{2}$ has been reported as 0, 200 (Bourdillon et al., 1982; Zhang and Wilson, 1993) and $1260 \mu \mathrm{mol} / 1$ (Bourdillon et al., 1982), respectively.

\subsection{Hydrogen delivery and detection}

The methods of $\mathrm{H}_{2}$ administration and analysis were those developed in this laboratory and described in detail in a previous publication (Fellows and Boutelle, 1993). Unlike the previously used method of gas administration, which involved passing lightweight polyethyletherketone (PEEK) HPLC tubing (I.D. 1.6 mm, O.D. $3.2 \mathrm{~mm}$; Anachem, Luton, UK) through channels in the dental acrylate made during the surgery, and bending them in such a way as to position two 0.4-mm holes about $5 \mathrm{~mm}$ beneath the rat's nostrils, the gas was administered to the animals by simply holding the PEEK tubing under the animal's snout at a similar distance for 10-20 s. This procedure was as effective as the previous method and was tolerated extremely well by the rats which exhibited normal behaviour while it was taking place. The PEEK tubing was connected through a flashback arrestor and a pressure regulator to a $\mathrm{H}_{2}$ cylinder (zero grade, BOC), with the gas flow controlled external to the rat's bowl. The gas was administered at approximately 5-min intervals and at a flow rate of $150 \mathrm{ml} / \mathrm{min}$.

Blood flow measurements were also performed in a similar manner to that described previously by Fellows and Boutelle (1993). Briefly, for each blood flow measurement, the LabVIEW program was started and the baseline recorded for $5 \mathrm{~s} . \mathrm{H}_{2}$ was then administered until the current had increased by $30-80 \mathrm{nA}$. The decay curve was collected for a $3-\mathrm{min}$ period. The first 30-60 $\mathrm{s}$ of the curve was neglected and the remaining 120-240 $\mathrm{s}$ were transferred to the analysis program. Here a first-order analysis plot of $\ln [i(t)-i$ (baseline) $]$ versus time $t$ was performed. If a linear plot was obtained, the slope was converted to blood flow (assuming a tissue partition coefficient of unity) according to the following formula:

$$
\begin{aligned}
\operatorname{rCBF}\left(\mathrm{ml} \cdot 100 \mathrm{~g}^{-1} \cdot \mathrm{min}^{-1}\right) & = \\
& \operatorname{slope}\left(\mathrm{s}^{-1}\right) \times 60 \mathrm{~s} \times 100 \mathrm{~g}
\end{aligned}
$$


When the semilog plot showed a clear break in the slope, the decay curves before and after the break point were analysed separately.

\subsection{Physiological stimulation}

Two forms of physiological stimulation were used; these were tail pinch and induced grooming. In the first, a paper clip was attached ca. $3 \mathrm{~cm}$ from the tip of the rat's tail for $5 \mathrm{~min}$; this produces a well characterised behaviour pattern which consists of gnawing, licking, eating and a general increase in the level of motor activity (Antelman et al., 1975). In the second, water was dripped from a plastic dropper onto the rat's snout until the animal engaged in a period (usually between 5 to $10 \mathrm{~min}$ ) of active grooming.

\section{Results and discussion}

For the comparison of simultaneous changes in tissue $\mathrm{O}_{2}$ and blood flow in response to neuronal activation, rats were implanted with a CPE in the left striatum and a Pt/Ir electrode in the right striatum. The techniques used for monitoring these changes were differential pulse amperometry (DPA), originally developed for the simultaneous measurement of changes in $\mathrm{O}_{2}$ and ascorbic acid in vivo (Lowry et al., 1996), and $\mathrm{H}_{2}$ clearance.

The application of a 5-min tail pinch resulted in an immediate and rapid increase in the $\mathrm{O}_{2}$ current signal $(\Delta I)$ recorded at the CPE by $10.8 \pm 1.9 \mathrm{nA}$ from a mean baseline of $-200 \pm 24 \mathrm{nA}(P<0.001$, eight tail pinches in two rats). On removal of the stimulus the current immediately began to fall and returned to baseline within ca. $10 \mathrm{~min}$. The $\mathrm{rCBF}$, calculated from the $\mathrm{H}_{2}$ clearance at the $\mathrm{Pt} / \mathrm{Ir}$ electrode, also showed an immediate increase from a basal value of $89 \pm 8 \mathrm{ml}(100$ $\mathrm{g})^{-1} \mathrm{~min}^{-1}$ to a maximum of $158 \pm 13 \mathrm{ml}(100 \mathrm{~g})^{-1}$ $\min ^{-1}(P<0.001)$, and returned to prestimulus levels ca. 16 min after the end of the stimulus. These basal and stimulated flow values are in good agreement with previous estimations made in awake animals: Basal, 93 $\mathrm{ml}(100 \mathrm{~g})^{-1} \mathrm{~min}^{-1}$ (Fellows and Boutelle, 1993) and $105 \mathrm{ml}(100 \mathrm{~g})^{-1} \mathrm{~min}^{-1}$ (Ohata et al., 1981); Stimulated $160 \mathrm{ml}(100 \mathrm{~g})^{-1} \mathrm{~min}^{-1}$ (Fellows and Boutelle, 1993). A typical example of the effect of a 5-min tail pinch on both $\mathrm{O}_{2}$ and blood flow is shown in Fig. 1A and $\mathrm{B}$, respectively.

As observed with tail pinch, stimulated grooming resulted in an immediate increase in striatal $\mathrm{O}_{2}$ levels by $6.2 \pm 1.1 \mathrm{nA}$ from a mean baseline of $-160 \pm 10 \mathrm{nA}$ $(P<0.001$, eight measurements in two rats). The signal rapidly returned to baseline (typically within $5 \mathrm{~min}$ ) when the animal stopped grooming. Values for $\mathrm{rCBF}$ rose from a mean basal level of $81 \pm 7 \mathrm{ml}(100 \mathrm{~g})^{-1}$ $\min ^{-1}$ to a maximum of $112 \pm 10 \mathrm{ml}(100 \mathrm{~g})^{-1} \mathrm{~min}^{-1}$
$(P<0.001)$. On cessation of activity values also returned to basal levels. Fig. 1C and D illustrate the effect of a typical period of grooming on striatal $\mathrm{O}_{2}$ and blood flow. Unlike tail pinch, where the period of stimulation is controlled by the application and removal of the paper clip from the rat's tail, induced grooming is more independent of the stimulus in that the behaviour is often characterised by periods of active grooming with intermittent rest periods. This is clearly illustrated in Fig. 1C and D by the biphasic increase in both the $\mathrm{O}_{2}$ signal and $\mathrm{rCBF}$ values which correspond to two periods of grooming separated by a period of inactivity. The spontaneous baseline fluctuations of the $\mathrm{O}_{2}$ current, also observed by others, (Clark and Lyons, 1958) were found to disappear during anaesthesia and after the death of the animal; this suggests that they reflect rapid changes in $\mathrm{O}_{2}$ associated with the awake, freely moving animal, and are not artifactual or due to electronic noise.

A correlation analysis of the changes in $\mathrm{O}_{2}$ currents and $\mathrm{rCBF}$ measurements resulting from both tail pinch and grooming is shown in Fig. 2. The correlation coefficient is $0.77(P<0.0001)$. The mean percentage increase in $\mathrm{rCBF}$ in response to tail pinch was $83 \pm$ $13 \%$, similar to the value of $98 \pm 16 \%$ previously reported for tail pinch by Fellows and Boutelle (1993). The maximum percentage increase during induced grooming was $37 \pm 4 \%$. Whereas absolute rCBF can be calculated from the $\mathrm{H}_{2}$ clearance values, the DPA reduction current at the CPE includes a large background signal typical of implanted CPEs. This is due to increased surface wetability resulting from removal of the insulating silicone oil by lipids, which constitute ap-
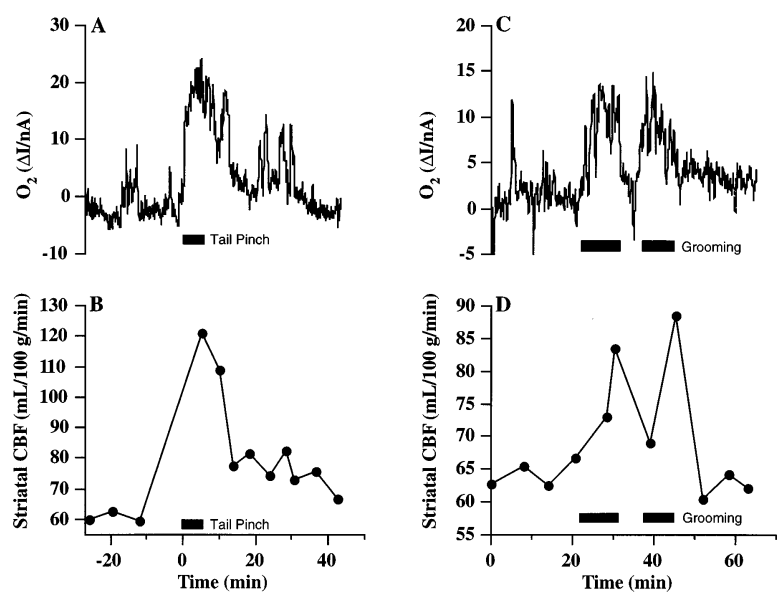

Fig. 1. Typical examples of the effect of a 5-min tail pinch (dark bar, $\mathrm{A}$ and $\mathrm{B}$ ) and induced grooming (dark bar, $\mathrm{C}$ and D) on striatal $\mathrm{O}_{2}$ and blood flow levels monitored simultaneously with bilaterally implanted carbon paste $\left(\mathrm{O}_{2}\right)$ and $\mathrm{Pt} / \mathrm{Ir}\left(\mathrm{H}_{2}\right.$ clearance $)$ electrodes. Absolute currents $(|\Delta I|)$ for $\mathrm{O}_{2}$ reduction recorded using differential pulse amperometry are shown in each case. Baseline currents of $190 \mathrm{nA}$ (tail pinch) and $165 \mathrm{nA}$ (grooming) have been subtracted. 


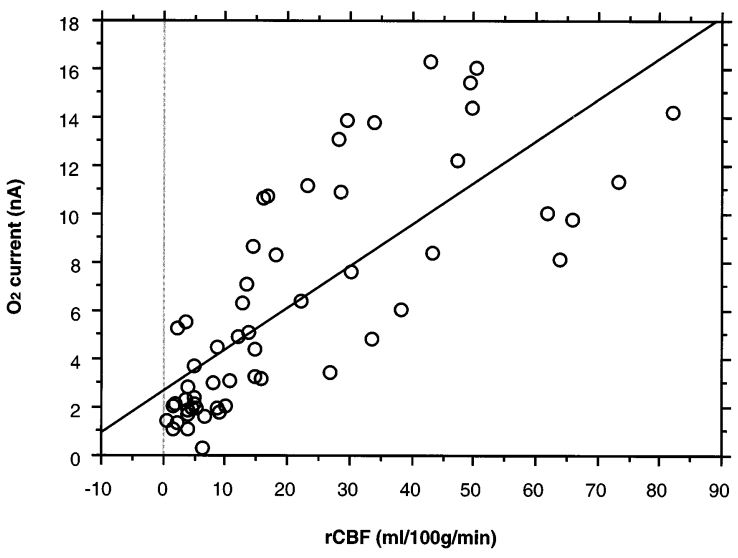

Fig. 2. A bivariate scattergram of changes in striatal $\mathrm{O}_{2}$ currents and rCBF measurements recorded simultaneously with bilaterally implanted carbon paste $\left(\mathrm{O}_{2}\right)$ and $\mathrm{Pt} / \mathrm{Ir}\left(\mathrm{H}_{2}\right.$ clearance $)$ electrodes. Data for both tail pinch and grooming stimulations have been pooled and baseline values for both variables have been subtracted.

proximately $40 \%$ of the dry mass of brain tissue (Ormonde and O’Neill, 1990; Lowry et al., 1996). However, using post in vivo calibrations (see Experimental conditions Section 2.5) the increases in $\mathrm{O}_{2}$ for tail pinch and grooming were converted to concentrations: $44 \pm 8$ $\mu \mathrm{mol} / 1$ (tail pinch) and $25 \pm 4 \mu \mathrm{mol} / 1$ (grooming). The $\mathrm{O}_{2}$ concentration in the extracellular fluid (ECF) is a dynamic balance between supply of $\mathrm{O}_{2}$ via blood flow in capillaries and $\mathrm{O}_{2}$ consumption associated with metabolism in cells. The range measured with implanted microelecrodes is from 5 to $50 \mu \mathrm{mol} / 1$ (Feng et al., 1988; Zimmerman and Wightman, 1991). Assuming a maximum ECF concentration of $50 \mu \mathrm{mol} / 1$, the above concentrations represent mean percentage increases of $88 \pm 15 \%$ and $50 \pm 9 \%$ for tail pinch and grooming, respectively. Although $\mathrm{O}_{2}$ utilisation increases during stimulated neuronal activity, the present results confirm previous findings that the rise in $\mathrm{rCBF}$ exceeds the increase in $\mathrm{O}_{2}$ utilisation resulting in a net increase in $\mathrm{O}_{2}$ (Leniger-Follert and Lübbers, 1976; Fox et al., 1988; Zimmerman et al., 1992). For this reason $\mathrm{O}_{2}$ currents provide an index of increases in $\mathrm{rCBF}$ only when such increases exceed $\mathrm{O}_{2}$ utilisation.

The measurement of dissolved $\mathrm{O}_{2}$ levels is generally obtained amperometrically using CPA at a noble metal microelectrode where the measured current is taken to be proportional to the dissolved $\mathrm{O}_{2}$ (Hitchman, 1978). The use of carbon-based electrodes as cathodes for $\mathrm{O}_{2}$ reduction instead of the more commonly used $\mathrm{Pt}$ has recently been reported by several groups (Paliteiro et al., 1987; Zimmerman and Wightman, 1991; Lowry et al., 1996). An example of the response of a CPE held at $-550 \mathrm{mV}$, the peak potential for $\mathrm{O}_{2}$ reduction at CPEs (Lowry et al., 1996), to a 5-min tail pinch is shown in
Fig. 3. The response characteristics were similar to those obtained with DPA; on application of the tail pinch there was an immediate and rapid increase in the $\mathrm{O}_{2}$ current which returned to baseline on removal of the stimulus. This indicates that increases in $\mathrm{O}_{2}$ monitored with CPA at a CPE may also be used as an index of increased blood flow under conditions of physiological stimulation.

Carbon electrodes have the advantage that they are less prone to surface poisoning and as such do not require the use of protecting membranes which are a characteristic of metal-based $\mathrm{O}_{2}$ electrodes including the most commonly used Clark electrode. Carbon electrodes are also more stable and in the case of CPEs have been found to be stable over several months in vivo (O'Neill and Fillenz, 1985). Recently, a new method for the measurement of dissolved $\mathrm{O}_{2}$ in vivo involving Nafion ${ }^{\mathrm{TM}}$ modified carbon fibre disk electrodes (CFEs) and fast cyclic voltammetry has been reported by Wightman's group (Zimmerman and Wightman, 1991; Zimmerman et al., 1992). As a fastscan technique this method also has advantages associated with subsecond time resolution. However, because of the small dimensions of CFEs (typically $10 \mu \mathrm{m}$ ) the concentration of $\mathrm{O}_{2}$ observed varies depending on the orientation of the electrode relative to the blood vessels and metabolically active sites. Since the dimension (125$\mu \mathrm{m}$ active internal diameter) of the CPEs used in this study is greater than the scale of a capillary zone $(<100 \mu \mathrm{m})$ (Silver, 1965), an average tissue $\mathrm{O}_{2}$ level should be detected, thus offering a practical advantage over the use of CFEs for $\mathrm{O}_{2}$ measurements.

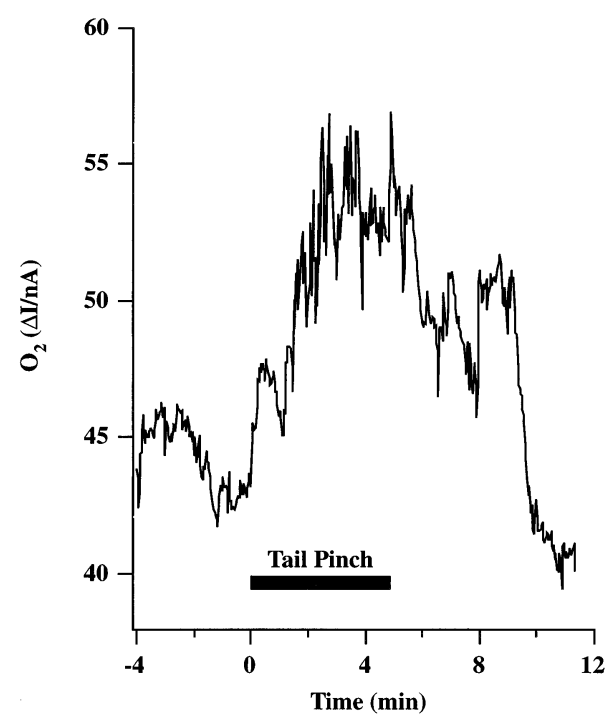

Fig. 3. An example of the effect of a 5-min tail pinch (dark bar) on striatal $\mathrm{O}_{2}$ levels recorded using constant potential amperometry at a carbon paste electrode. The signal shown is the absolute current for $\mathrm{O}_{2}$ reduction. 


\section{Conclusions}

Tail pinch and induced grooming resulted in simultaneous increases in striatal $\mathrm{O}_{2}$ and $\mathrm{rCBF}$ recorded with bilaterally implanted carbon paste and $\mathrm{Pt} / \mathrm{Ir}\left(\mathrm{H}_{2}\right.$ clearance) electrodes respectively. The detection of changes in $\mathrm{O}_{2}$ concentration at implanted CPEs was examined using two different voltammetric techniques: differential pulse amperometry and constant potential amperometry. Both techniques were found to respond to increases in $\mathrm{O}_{2}$ concentration associated with neuronal activation. These results suggest that under conditions of physiological stimulation, when supply of $\mathrm{O}_{2}$ from the blood stream shows a substantial increase over utilisation, the simple direct voltammetric measurement of $\mathrm{O}_{2}$ in brain tissue with a CPE can be used as a reliable index of increases in $\mathrm{rCBF}$, resulting in an improvement in time resolution from $5 \mathrm{~min}\left(\mathrm{H}_{2}\right.$ clearance) to $<1 \mathrm{~s}$ (amperometry).

\section{Acknowledgements}

J.P.L. gratefully acknowledges the European Commission for a research training fellowship under the Human Capital and Mobility programme (Grant No. ERB CHB ICT94 1353). We thank Dr. Robert D. O'Neill for helpful discussions.

\section{References}

Antelman, S.M., Szechtman, H., Chin, P. and Fisher, A.E. (1975) Tail pinch-induced eating, gnawing and licking behaviour in rats: dependence on the nigrostriatal dopamine system, Brain Res., 99: $319-337$.

Aukland, K., Bower, B.F. and Berliner, R.W. (1964) Measurement of local blood flow with hydrogen gas, Circ. Res., 14: 164-187.

Aukland, K. (1965) Hydrogen polarography in measurement of local blood flow, theoretical and empirical basis, Acta Neurol. Scand., 41: $42-44$.

Bourdillon, C., Thomas, V. and Thomas, D. (1982) Electrochemical study of D-glucose oxidase autoinactivation, Enzyme Microb. Technol., 4: 175-180.

Bray, L., Lartaud, I., Muller, F., Atkinson, J. and Capdeville, C. (1991) Effects of the angiotensin I converting enzyme inhibitor perindopril on cerebral blood flow in awake hypertensive rats, Am. J. Hypertens., 4: 246S-252S.

Clark Jr., L.C. and Lyons, C. (1958) Studies of a glassy carbon electrode for brain polarography with observations on the effect of carbonic anhydrase inhibition, Ala. J. Med. Sci., 2: 353-359.

Endo, Y., Jinnai, K., Endo, M., Fujita, K. and Kimura, F. (1990) Diurnal variation of cerebral blood flow in rat hippocampus, Stroke, 21: 1464-1469.

Fellows, L.K. and Boutelle, M.G. (1993) Rapid changes in extracellular glucose levels and blood flow in the striatum of the freely moving rat, Brain Res., 604: 225-231.

Feng, Z.-C., Roberts, E.L., Sick, T.J. and Rosenthal, M. (1988) Depth profile of local oxygen tension and blood flow in rat cerebral cortex, white matter and hippocampus, Brain Res., 445: $280-288$.
Fieschi, C. (1966) Blood flow measurements in the brains of cats by analysis of the clearance curves of hydrogen gas with implanted electrodes and of $\mathrm{Kr} 85$ with external counting of gamma activity. In The Cerebral Circulation in Research and Clinic (The Congress Proceedings of the 2nd International Salzburg Symposium 1964), Vienna, Hollinek, pp. 180-186.

Fox, P.T., Raichle, M.E., Mintun, M.A. and Dence, C. (1988) Nonoxidative glucose consumption during focal physiologic neural activity, Science, 241: 462-464.

Gotoh, F., Meyer, J.S. and Ebihara, S. (1966) Continuous recording of human cerebral blood flow and metabolism: methods of electronic monitoring of arterial and venous gases and electrolytes, Med. Res. Eng., 5: 13-19.

Haining, J.L., Turner, M.D. and Pantall, R.M. (1968) Measurement of local cerebral blood flow in the unanesthetised rat using a hydrogen clearance method, Circ. Res., 23: 313-324.

Hitchman, M.L. (1978) Measurement of Dissolved Oxygen, Wiley, New York.

Leniger-Follert, E. and Lübbers, D.W. (1976) Behavior of microflow and local $\mathrm{Po}_{2}$ of the brain cortex during and after electrical stimulation, Pflügers Arch., 366: 39-44.

Lowry, J.P., Boutelle, M.G., O’Neill, R.D. and Fillenz, M. (1996) Charcterisation of carbon paste electrodes in vitro for simultaneous amperometric measurement of changes in oxygen and ascorbic acid concentrations in vivo, Analyst, 121: 761-766.

Morton, D.B. and Griffiths, P.H.M. (1985) Guidelines on the recognition of pain, distress and discomfort in experimental animals and an hypothesis for assessment, Vet. Res., 116: 431-436.

O'Neill, R.D. (1993) Sensor-tissue interactions in neurochemical analysis with carbon paste electrodes in vivo, Analyst, 118: 433-438.

O’Neill, R.D. and Fillenz, M. (1985) Detection of homovanillic acid in vivo using microcomputer-controlled voltammetry: simultaneous monitoring of rat motor activity and striatal dopamine release, Neuroscience, 14: 753-763.

O’Neill, R.D., Grunewald, R.A., Fillenz, M. and Albery, W.J. (1982) Linear sweep voltammetry with carbon paste electrodes in rat striatum, Neuroscience, 7: 1945-1954.

Ohata, M., Fredericks, W.R., Sundaram, U. and Rapoport, S.I. (1981) Effects of immobilization stress on regional cerebral blood flow in the conscious rat, J. Cereb. Blood Flow Metab., 1: $187-194$.

Ormonde, D.E. and O’Neill, R.D. (1990) The oxidation of ascorbic acid at carbon paste electrodes. Modified response following contact with surfactant, lipid and brain tissue, J. Electroanal. Chem. Interfac. Electrochem., 279: 109-121.

Paliteiro, C., Hamnett, A. and Goodenough, J.B. (1987) The electroreduction of oxygen at pyrolytic graphite, J. Electroanal. Chem. Interfac. Electrochem., 233: 147-159.

Silver, I.A. (1965) Some observations on the cerebral cortex with an ultra-micro, membrane covered, oxygen electrode, Med. Electron. Biol. Eng., 3: 377-387.

Wolfensohn, S. and Lloyd, M. (1994) Handbook of Laboratory Animal Management and Welfare, Oxford University Press, Oxford.

Young, W. (1980) $\mathrm{H}_{2}$ clearance measurement of blood flow: a review of technique and polarographic principles, Stroke, 11: 552-564.

Zhang, Y.N. and Wilson, G.S. (1993) In vitro and in vivo evaluation of oxygen effects on a glucose oxidase based implantable glucose sensor, Anal. Chim. Acta, 281: 513-520.

Zimmerman, J.B., Kennedy, R.T. and Wightman, R.M. (1992) Evoked neuronal activity accompanied by transmitter release increases oxygen concentration in rat striatum in vivo but not in vitro, J. Cereb. Blood Flow Metab., 12: 629-637.

Zimmerman, J.B. and Wightman, R.M. (1991) Simultaneous electrochemical measurement of oxygen and dopamine in vivo, Anal. Chem., 63: 24-28. 